\title{
Mannitol Amendment as a Carbon Source in a Bean-based Formulation Enhances Biocontrol Efficacy of a 2,4-diacetylphloroglucinol-producing Pseudomonas sp. NJ134 Against Tomato Fusarium Wilt
}

\author{
Beom Ryong Kang \\ Environment-Friendly Agricultural Research Institute, Jeollanamdo Agricultural Research and Extension Services, Naju 520- \\ 715 , Korea \\ (Received on October 26, 2011; Revised on November 13, 2011; Accepted on November 16, 2011)
}

Fusarium wilt caused by Fusarium oxysporum has become a serious problem world-wide and relies heavily on chemical fungicides. We selected Pseudomonas sp. NJ134 to develop an effective biocontrol strategy. This strain shows strong antagonistic activity against $F$. oxysporum. Biochemical analyses of ethyl-acetate extracts of $\mathrm{NJ134}$ culture filtrates showed that 2,4-diacetylphloroglucinol (DAPG) was the major compound inhibiting in vitro growth of $F$. oxysporum. DAPG production was greatly enhanced in the $\mathrm{NJ134}$ strain by adding mannitol to the growth media, and in vitro antagonistic activity against $\boldsymbol{F}$. oxysporum increased. Bioformulations developed from growth of $\mathrm{NJ134}$ in sterile bean media with mannitol as the carbon source under plastic bags resulted in effective biocontrol efficacy against Fusarium wilt. The efficacy of the bioformulated product depended on the carbon source and dose. Mannitol amendment in the bean-based formulation showed strong effective biocontrol against tomato Fusarium wilt through increased DAPG levels and a higher cell density compared to that in a glucose-amended formulation. These results suggest that this bioformulated product could be a new effective biocontrol system to control Fusarium wilt in the field.

Keywords : antibiotics, soilborne disease, bioformulation, nutrient, long term survival

Fusarium wilt caused by Fusarium oxysporum is a serious soilborne disease in tomato cultivation areas worldwide (Ishikawa et al., 2005). The rapid adoption of organic agriculture in the past decades has dramatically increased the demand for biopesticides that can be used to control tomato Fusarium wilt. Several antagonist microorganisms with broad-spectrum activity show promise for suppressing tomato Fusarium wilt. Biocontrol agents such as Pseudo-

\footnotetext{
*Corresponding author.

Phone) +82-61-330-2515, FAX) +82-61-336-4076

E-mail) brkang@korea.kr
}

monas spp., the fungus Trichoderna spp., and non-pathogenic Fusarium have reduced tomato Fusarium wilt in greenhouse experiments (Shishido et al., 2005; Yigit and Dikilitas, 2007). A talc-based bioformulation of Streptomyces sp. has been used to control Fusarium wilt in the greenhouse (Anitha and Rabeeth, 2009).

Numerous fluorescent Pseudomonas spp. have been isolated and characterized for their ability to suppress soilborne diseases through the production of various secondary metabolites, such as phenazines, pyrrolnitrin, and 2,4diacetylphloroglucinol (DAPG) (Keel et al., 1996). DAPG is a polyketide antibiotic with broad spectrum antimicrobial properties and is produced by fluorescent Pseudomonas spp. of diverse genotypes and geographic origins (Keel et al., 1996; Mavrodi et al., 2001; McSpadden-Gardener et al., 2000). Fluorescent pseudomonads that produce DAPG play a key role in the natural biological control of most important crop diseases, such as tomato crown and root rot, wheat take-all, black root rot of tobacco or cucumber, sugar damping off, and tomato Fusarium wilt (Dwivedi and Johri, 2003; Keel et al., 1996; KeU et al., 1992; Nowak-Thompson et al., 1994).

The growth medium and nutrients affect the levels of antibiotics and population densities in biocontrol bacteria. In Pseudomonas spp., the antibiotic DAPG is produced at high levels in the presence of glucose, gluconic acid, and zinc (Duffy and Défago, 1997; 1999; Werra et al., 2009). Although several potential biocontrol agents to control tomato Fusarium wilt have been isolated and characterized, no reports are available on effective biocontrol in the field.

For development of biological control agents against tomato Fusarium wilt, strain NJ134 was isolated from rhizosphere and suppressive soils in Jeonnam province, South Korea (Lee, 2009). A rhizobacterium NJ134 showed most effective inhibition against mycelial growth of the pathogen (KACC 40037). Based on 16S ribosomal DNA sequence analysis, the bacterial strain was identified as Pseudomonas sp. (GenBank: FJ627993.1, National Center for Biotechnology Information (NCBI), U.S.A.). An anti- 
fungal compound purified from $\mathrm{NJ} 134$ cultures was a polyketide, 2,4-diacetylphloroglucinol (DAPG) by GCMS, IR, and NMR analysis (Kang, 2011 submitted paper).

The main goal of this study was to develop an effective bioformulation for the DAPG producer Pseudomonas sp. NJ134 in a cost-effective growth medium containing mannitol and sucrose, ect. as the carbon source. The formulated bacterial product was tested to determine biocontrol efficacy and long term survival. Additionally, the most effective dosages were determined for efficient suppression of Fusarium tomato wilt under field conditions.

We demonstrated that Pseudomonas sp. NJ134 produced DAPG as a major antibiotic to inhibit $F$. oxysporum growth and control tomato Fusarium wilt. Fluorescent pseudomonads produce various antibiotics, such as phenazines, pyrrolnitrin, and DAPG, and these secondary metabolites play important roles in the biocontrol of crop diseases (Keel et al., 1996). The antifungal activity of NJ134 was extracted from culture medium using ethyl acetate. Antibiotic production by strain NJ134 in culture was detected by methods described previously (Whister et al., 2000). Strain NJ134 was grown in $5 \mathrm{ml}$ of modified $\mathrm{KB}$ (proteose peptone \#3 20 g, $\mathrm{K}_{2} \mathrm{HPO}_{4} 1.5 \mathrm{~g}, \mathrm{MgSO}_{4} \cdot 7 \mathrm{H}_{2} \mathrm{O} 0.4 \mathrm{~g}$ per L) containing $1 \%$ $(\mathrm{wt} / \mathrm{v})$ mannitol or glucose, respectively. High performance liquid chromatography analyses of the NJ134 ethyl acetate extracts showed that the peak with an elution time of 3.4 min had the highest antifungal activity (data not shown). DAPG $\left(0.07 \mu \mathrm{g} / \mathrm{ml} / 10^{5}\right)$ colony forming units (cfu) was produced by the NJ134 strain during the stationary phase after growth on KB with glucose. However, adding mannitol significantly increased DAPG levels by approximately 50 -fold to $3.97 \mu \mathrm{g} / \mathrm{ml} / 10^{5}$ cfu (Table 1). Production of antibiotic com-pounds is influenced by the presence of different carbon sources. In P. chlororaphis O6, pyrro-
Initrin production is eliminated by glucose in the growth medium, whereas phenazine production is enhanced (Park et al., 2011).

In this study, we demonstrated that very high levels of DAPG were produced by Pseudomonas sp. NJ134 using mannitol in the growth medium. In addition, strain NJ134 showed significantly higher cell densities with the addition of mannitol $\left(1.72 \times 10^{9} \mathrm{cfu} / \mathrm{ml}\right)$ compared to amendments with glucose, $1.63 \times 10^{8} \mathrm{cfu} / \mathrm{ml}$ (Table 1).

More profound inhibition of $F$. oxysporum was observed with the NJ134 strain grown in mannitol than that with glucose as the sole carbon source (Table 1). DAPG production was about 1.5 times higher when cells were grown with mannitol as the sole carbon source than when sucrose was the carbon source. However, the others media was poorly produced in these media in which lactose and glucose were used as a sole carbon source. The NJ134 conditions that produced significant amounts of DAPG and suppressed the pathogen could have been relatively high in mannitol content. Glucose has been used to optimize pyrrolnitrin (PLT) production by $P$. fluorescens HV37a (Douglas and Gutterson, 1986) and DAPG by $P$. fluorescens Pf-5 (Nowak-Thompson et al., 1994), whereas it does not improve PLT production by some fluorescent pseudomonads (Karus and Loper, 1995; Park et al., 2011; Shanahan et al., 1992). Thus, the production of biocontrol agents is influenced by the carbon source in the medium (Park et al., 2011; Shanahan et al., 1992; Yuan et al., 1998). Ethanol as the sole carbon source enhances the production of PLT and DAPG by P. fluorescens S272 (Yuan et al., 1998), rhamnolipids by $P$. aeruginosa and Pseudomonas strain BOP100 (Matsufuji et al., 1997; Osman et al., 1996). Pyoluteorin production by $P$. fluorescens Pf-5 is promoted in glucose media, but less pyoluteorin is produced with

Table 1. Effect of carbon source on antibiotic production, density, and in vitro antifungal activity by Pseudomonas strain NJ134

\begin{tabular}{lccc}
\hline \hline Carbon source $^{\mathrm{a}}$ & $\begin{array}{c}2,4-\text { diacetylphloroglucinol } \\
\left(\mu \mathrm{g} / \mathrm{ml} / 10^{5} \mathrm{cfu}\right)^{\mathrm{b}}\end{array}$ & $\begin{array}{c}\text { Population density } \\
(\mathrm{cfu} / \mathrm{ml})^{\mathrm{c}}\end{array}$ & ${\text { Inhibition rate }(\%)^{\mathrm{d}}}^{\mathrm{c}}$ \\
\hline Mannitol & $3.97 \pm 0.12 \mathrm{a}^{\mathrm{e}}$ & $1.72 \times 10^{9} \mathrm{a}$ & $83.3 \pm 5.52 \mathrm{a}$ \\
Glucose & $0.07 \pm 0.02 \mathrm{~d}$ & $1.63 \times 10^{8} \mathrm{~b}$ & $66.4 \pm 2.17 \mathrm{c}$ \\
Sucrose & $3.01 \pm 0.08 \mathrm{ab}$ & $1.19 \times 10^{9} \mathrm{ab}$ & $76.1 \pm 2.48 \mathrm{ab}$ \\
Glycerol & $0.75 \pm 0.05 \mathrm{~b}$ & $1.01 \times 10^{9} \mathrm{ab}$ & $74.5 \pm 5.70 \mathrm{~b}$ \\
Lactose & $0.31 \pm 0.04 \mathrm{c}$ & $4.52 \times 10^{8} \mathrm{~b}$ & $68.2 \pm 4.06 \mathrm{bc}$ \\
\hline
\end{tabular}

${ }^{a}$ Bacteria was grown for 7 days in modified KB containing different $1 \%$ carbon sources.

' 2,4-diacetylphloroglucinol (DAPG) production was determined by high performance liquid chromatography and is expressed as the amount of DAPG produced per population unit $\left(10^{5} \mathrm{cfu}\right)$ of strain NJ134.

${ }^{\mathrm{C}}$ Colony forming units were determined by dilution plating on KB agar.

${ }^{\mathrm{d}}$ Inhibition rates were done on the petri dish containing PDA. A 4-mm mycelial disc from a 7-day-old F. oxysporum culture in PDA was placed on the opposite side vertical to the bacterial $(30 \mu \mathrm{l})$ dropped disc in the petri dish. The growth of the fungus was inhibited when it grew toward the bacterial colony, and the inhibition zone was measured from the edge of mycelium to the bacterial colony edge at 7 days after incubation. Inhibition rates of the products are represented by the following equation: inhibition rate $(\%)=(\mathrm{R}-\mathrm{r}) / \mathrm{R} \times 100$. $\mathrm{R}$ is the maximum radius of the fungal colony away from the bacterial colony, and $\mathrm{r}$ is the radius of the fungal colony opposite the bacterial colony.

${ }^{\mathrm{e}}$ Means within a column followed by a common letter are not significantly different $(P=0.05)$ by Duncan's multiple range test. 
glycerol (Karus and Loper, 1995). These results suggest that DAPG produced by Pseudomonas sp. NJ134 was a major antibiotic against $F$. oxysporum, and that DAPG production was greatly influenced by the carbon source.

We developed a formulation using a mixture of cracked lupin bean (Lupinus luteus) and fluorescent Pseudomonas strain NJ134, which effectively inhibited $F$. oxysporum growth in vitro. Briefly, strain NJ134 was grown on liquid KB medium with different carbon sources for 48 hour on a shaker $(150 \mathrm{rpm})$ at $26^{\circ} \mathrm{C}$. Beans $(1 \mathrm{~kg})$ as carrier materials were cracked slightly with a wooden hammer and autoclaved for $30 \mathrm{~min}$ on 2 consecutive days. Bacterial cultures were adjusted to $1 \times 10^{8} \mathrm{cfu} / \mathrm{ml}$, and $500 \mathrm{ml}$ of bacterial suspension was added to the $1 \mathrm{~kg}$ of sterilized beans with $1 \%$ different carbon sources. Bacterial cultures were mixed with amendments in sterile polythene bags, sealed, and incubated at $26^{\circ} \mathrm{C}$ for the defined times. The $10 \mathrm{~g}$ formulated product was sampled at 7, 30, 60 days after incubations to measure the production of DAPG and viable cell densities (Table 2). DAPG production of purified compound of formulation amendment mannitol showed a major peak at a retention time of $4.58 \mathrm{~min}$ that corresponded to the peak obtained for the DAPG standard $(2,4-$ diacetylphlorogulcinol, Toronto Research Chemicals Inc.) at a retention time of $4.48 \mathrm{~min}$ after 60 days (Supplementary Fig. 1). The production titer was significantly higher about 2.7 times in mannitol medium than in glucose medium. When strain NJ134 was grown on formulated mannitol, it was used for optimization of DAPG production. However, glucose did not improve for the antibiotic production. Significantly higher DAPG production occurred in the bean-based formulation, and the highest in vitro antifungal activity against $F$. oxysporum was observed when the NJ134 strain was grown with added mannitol (Table 2). We demonstrated that the bioformulated DAPG producer NJ134 showed strong antifungal activity against F. oxysporum in media with added mannitol and was effective for suppressing tomato Fusarium wilt.

We examined long-term survival rates to investigate whether the nutrient amendment affected long-term survival under room temperature storage conditions. The longterm survival of the NJ134 cultures grown in glucose or control conditions was significantly less compared with that of the NJ134 cultures grown in media amended with mannitol for 60 days in single inoculation studies (Table 2). The growth medium and nutrients affect population densities in biocontrol bacteria. Our results are similar to those showing that high molecular weight compounds such as sucrose enhance survival of Pseudomonas and Enterobacteriaceae (Caesar and Burr, 1991) or improve survival of Rhizobium spp. in powder formulations (Bushby and Marshall, 1977). Also, the synergistic effects of the mannitol in a bean-based formulation could be stable in the rhizosphere. Activation of antibiotic substances and increased population density has been reported (KeU et al., 1992; Leeman et al., 1996; Raaijmakers et al., 1999; Wood et al., 1997). We do not have direct evidence on enhanced long-term survival in the presence of mannitol. We are currently investigating the possible roles of mannitol in long-term survival. Mannitol acts as a compatible solute and osmoprotectant. In Gram-negative bacteria, cell viability under nutrient limiting conditions, such as those during the stationary phase, gradually diminish because of acid and oxidative stresses (Ferreira et al., 2001; Kets et al., 1996; Nystrom, 2001). The natural environments in which either introduced or naturally occurring DAPG-producing

Table 2. Effect of 2,4-diacetylphloroglucinol (DAPG) production, survival, and in vitro inhibition rate of formulated $P$. strain NJ134 with different carbon sources

\begin{tabular}{|c|c|c|c|c|c|}
\hline \multirow{2}{*}{ Carbon source ${ }^{\mathrm{a}}$} & \multirow{2}{*}{$\begin{array}{c}\text { DAPG } \\
(\mu \mathrm{g} / \mathrm{g} \text { of formulation })^{\mathrm{b}}\end{array}$} & \multicolumn{3}{|c|}{$\begin{array}{l}\mathrm{cfu} / \mathrm{g} \text { of formulation }{ }^{\mathrm{c}} \\
\text { at different days after treatment }\end{array}$} & \multirow{2}{*}{ Inhibition rate $(\%)^{\mathrm{d}}$} \\
\hline & & 7 & 30 & 60 & \\
\hline Mannitol & $0.19 \pm 0.02 \mathrm{a}^{\mathrm{e}}$ & $8.27 \times 10^{8} \mathrm{a}$ & $2.97 \times 10^{8} \mathrm{a}$ & $1.65 \times 10^{7} \mathrm{a}$ & $71.5 \pm 0.73 \mathrm{a}$ \\
\hline Glucose & $0.07 \pm 0.01 \mathrm{~b}$ & $5.79 \times 10^{7} \mathrm{~b}$ & $1.90 \times 10^{6} \mathrm{~b}$ & $2.41 \times 10^{5} \mathrm{~b}$ & $65.5 \pm 0.52 b$ \\
\hline Control & $0.04 \pm 0.01 \mathrm{c}$ & $4.06 \times 10^{6} \mathrm{~b}$ & $2.20 \times 10^{4} \mathrm{~b}$ & $8.05 \times 10^{2} \mathrm{~b}$ & $40.9 \pm 1.51 \mathrm{c}$ \\
\hline
\end{tabular}

${ }^{a}$ Bacterial suspension was mixed with $1 \mathrm{~kg}$ sterilized beans and $1 \%$ different carbon sources, and then dried. The control was treated with the formulated product without a carbon source.

${ }^{b}$ DAPG production was determined by liquid chromatography/mass spectrometry (LC/MS/MS) and is expressed as the amount of DAPG produced per $1 \mathrm{~g}$ unit (bean-based formulation) by strain NJ134.

${ }^{\mathrm{c}}$ Colony forming units were determined by dilution plating on $\mathrm{KB}$ agar containing glycerol.

${ }^{\mathrm{d}}$ Inhibition rates were done on the petri dish containing PDA. A 4-mm mycelial disc from a 7-day-old F. oxysporum culture in PDA was placed on the opposite side vertical to the bacterial $(30 \mu \mathrm{l})$ dropped disc in the petri dish. The growth of the fungus was inhibited when it grew toward the bacterial colony, and the inhibition zone was measured from the edge of mycelium to the bacterial colony edge at 7 days after incubation. Inhibition rates of the products are represented by the following equation: inhibition rate $(\%)=(R-r) / R \times 100$. $R$ is the maximum radius of the fungal colony away from the bacterial colony, and $r$ is the radius of the fungal colony opposite the bacterial colony.

${ }^{\mathrm{e}}$ Means within a column followed by a common letter are not significantly different $(P=0.05)$ by Duncan's multiple range test. 
Pseudomonas spp. function are subjected to change under abiotic and biotic conditions. Several abiotic factors such as specific carbon and nitrogen sources have been identified or proposed to influence in situ antibiotic production by Pseudomonas spp. (Duffy and Defago, 1997; Shanahan et al., 1992; Slininger and Jackson, 1992). The biotic factors that may play an important role in the regulation of antibiotic production include the cell density of the producing strain (Raaijmakers et al., 1999).

A bean-based bioformulation with different carbon sources was assessed for efficiency in controlling Fusarium wilt in tomatoes under greenhouse conditions. The different formulation treatments were mixed in plastic pots $(200 \times 40 \times$ $30 \mathrm{~cm}$ ) containing an autoclaved mixture of a 1:1 (v:v) ratio of vermiculite and sand. Leaf-stage tomato seedling ( $\mathrm{n}=$ 18-20; Unicorn, Hungnong Seeds, Korea) were transferred to pots treated with the formulation. After 7 days in a planting tray, the pathogen was inoculated with infested soil (Marjan et al., 2003).

The pathogen was cultured in aerated CMCLM (15 g of carboxymethyl cellulose, $1 \mathrm{~g}$ of $\left(\mathrm{NH}_{4}\right)_{2} \mathrm{SO}_{4}, 1 \mathrm{~g}$ of $\mathrm{KH}_{2} \mathrm{PO}_{4}$, $0.5 \mathrm{~g}$ of $\mathrm{MgSO}_{4} \cdot 7 \mathrm{H}_{2} \mathrm{O}$, and $1 \mathrm{~g}$ of yeast extract per liter) medium at $25^{\circ} \mathrm{C}$ (Cappellini and Peterson, 1965). After 21 days of growth, cultures were filtered through sterile glass wool to remove mycelia mats. Macroconidia were harvested by centrifugation at $8,000 \times g$ for $20 \mathrm{~min}$, resuspended in $10 \mathrm{mM} \mathrm{MgSO}_{4}$, and mixed through a potting soil-sand mixture $(12: 5, \mathrm{v} / \mathrm{v})$ to a density of $1 \times 10^{3} \mathrm{spore} / \mathrm{g}$ of soil. Inoculated soil was incubated in polyethylene bags for 3 days at $25{ }^{\circ} \mathrm{C}$ before use in the potting soil bioassays by the pathogen. 60 days after treatment, plants were scored for both external wilting and internal browning symptoms (Leeman et al., 1996). The experiment was conducted two times with 30 plants per treatments. An assessment of the biocontrol activity of the bioformulated product against tomato Fusarium wilt showed that the mannitol amendment affected biocontrol efficacy. The severity of tomato Fusarium wilt was reduced significantly after soil application of the product, and the biocontrol efficacy of the formulated product amended with mannitol was much higher (Table 3). For both bioformulated products amended with mannitol and glucose, the higher dose (300 g/pot) showed significantly higher biocontrol efficacy compared to that of the lower dosages (100 or $200 \mathrm{~g} / \mathrm{pot})$. Furthermore, Pseudomonas sp. NJ134 showed significantly higher cell densities in the formulated product amended with mannitol $(5.33 \times$ $10^{6} \mathrm{cfu} / \mathrm{g}$ of root) compared to that with a glucose amendment $\left(6.33 \times 10^{4} \mathrm{cfu} / \mathrm{g}\right.$ of root; data not shown $)$ at 60 days after treatment. Although bioformulated products for Gram-positive bicontrol bacteria, such endospore forming Bacillus strains, have been developed and commercialized, only a few biopesticides for Gram-negative bacteria have
Table 3. Effect of carbon source and dosage on disease suppression by formulated strain NJ134 in the greenhouse

Disease index $(0-5)^{b}$

\begin{tabular}{lccc} 
Carbon source $^{\mathrm{a}}$ & \multicolumn{3}{c}{ at dosage of application (g/pot) } \\
\cline { 2 - 4 } & 100 & 200 & 300 \\
\hline Mannitol & $1.5 \pm 0.46 \mathrm{a}^{\mathrm{e}}$ & $1.4 \pm 0.20 \mathrm{a}$ & $0.7 \pm 0.15 \mathrm{a}$ \\
Glucose & $2.7 \pm 0.11 \mathrm{~b}$ & $2.1 \pm 0.23 \mathrm{~b}$ & $1.4 \pm 0.16 \mathrm{~b}$ \\
Control & $3.3 \pm 0.12 \mathrm{~b}$ & $3.0 \pm 0.22 \mathrm{c}$ & $2.9 \pm 0.10 \mathrm{c}$ \\
Control (Bean) & $3.9 \pm 0.31 \mathrm{c}$ & $3.5 \pm 0.30 \mathrm{c}$ & $4.1 \pm 0.13 \mathrm{~d}$
\end{tabular}

${ }^{a}$ Bacteria was grown for 2 days in modified $\mathrm{KB}$ containing $1 \%$ carbon sources. Bacterial suspension (500) $\mathrm{ml}$ containing $1 \times 10^{9} \mathrm{cfu} / \mathrm{ml}$ was added to $1 \mathrm{~kg}$ of carrier with $1 \%$ carbon source and mixed well in sterile polythene bags, sealed, and then dried. The bean-based formulations were incorporated with application dosages in a greenhouse. Control (bean) was the formulation product without the bacterium and carbon source. The experiment was conducted two times with 30 plants per treatment.

${ }^{\mathrm{b}}$ The disease index was as follows: $0(0 \%$ disease severity $)=$ healthy plant, all leaves were green; $1(1-24 \%$ disease severity $)=$ the first leaf yellow; $2(25-49 \%)=$ lower leaves yellow; $3(50-74 \%)=$ lower leaves dead and some upper leaves yellow; $4(75-99 \%)=$ upper leaves wilted, lower leaves dead; $5(100 \%)=$ dead plant.

${ }^{\mathrm{e}}$ Means within a column followed by a common letter are not significantly different $(P=0.05)$ by Duncan's multiple range test.

been reported due to the short shelf life. An effective biocontrol bioformulation containing a complex of chitinaseproducing biocontrol bacterial strains and chitin under large batch conditions has been developed and used effectively to control Phytophthora blight in pepper (Kim et al., 2008) and Alternaria blight and anthracnose disease in Korean ginseng under field conditions (Kim et al., 2008; 2010).

In conclusion, our results indicate that DAPG in the NJ134 formulation is a major player and enhanced protection against Fusarium wilt. A bean-based formulation can be used as nutrients to grow Gram-negative bacterial strains in a cost-effective way. Adding mannitol can be used to aid in the production of high DAPG levels and long-term survival in the NJ134 bioformulated products. Culture suspensions of bioformulated products could be effective to control tomato Fusarium wilt, because of the high DAPG production levels and sustainable long-term survival. This result showed the usefulness of the formulation for controlling tomato wilt and indicated the feasibility of commercial production of this product. This study also demonstrated that using a mannitol source for the strain NJ134 strain to produce DAPG regulates the density of tomato Fusarium wilt.

We developed an effective bioformulated product to control tomato Fusarium wilt and to increase shelf life of the product. The formulation can serve as biocontrol management for agricultural systems to increase productivity, as the action of such bacteria is highly specific, ecofriendly, and cost-effective (Commarea et al., 2002; Vidhyasekaran 
et al., 1997). In addition, the usefulness of the formulation in the control of tomato wilt indicates it feasibility as a commercial product. The biocontrol activity and long-term survival of the DAPG producer in the bioformulation was greatly affected by mannitol in the medium, because it increased DAPG production. The effect of mannitol as a regulator of secondary metabolism may be linked to differing biocontrol efficacies of biocontrol bacteria under field conditions, as the level of carbon sources available to bacteria vary substantially.

\section{Acknowledgement}

This work was supported by a grant from the Korea Institute of Planning and Evaluation for Technology in Food, Agriculture, Forestry, and Fisheries (311019-03-1-HD120), Ministry for Food, Agriculture, Forestry, and Fisheries, Republic of Korea.

\section{References}

Anitha, A. and Rabeeth, M. 2009. Control of Fusarium wilt of tomato by bioformulation of Streptomyces griseus in green house condition. Afr. J. Basic Appl. Sci. 1:9-14.

Bushby, H. V. A. and Marshall, K. C. 1977. Some factors affecting the survival of root-nodule bacteria on desiccation. Soil Biol. Biochem. 9:143-147.

Caesar, A. J. and Burr, T. J. 1991. Effect of conditioning, betaine, and sucrose on survival of rhizobacteria in powder formulations. Appl. Environ. Microbiol. 57:168-172.

Cappellini, R. A. and Peterson, J. L. 1965. Macroconidium formation in submerged cultures by a nonsporulating strain of Gibberella zeae. Mycologia 57:962-966.

Commarea, R. R., Nandakumara, R., Kandana, A., Sureshb, S., Bharathib, M., Raguchandera, T. and Samiyappana, R. 2002. Pseudomonas fluorescens based bio-formulation for the management of sheath blight disease and leaffolder insect in rice. Crop Protect. 21:671-677.

Douglas, W. J. and Gutterson, N. I. 1986. Multiple antibiotics produced by Pseudomonas fluorescens HV37a and their differential regulation by glucose. Appl. Environ. Microbiol. 52:11831189.

Duffy, B. K. and Défago, G. 1997. Zinc improves biocontrol of Fusarium crown and root rot of tomato by Pseudomonas fluorescens and represses the production of pathogen metabolites inhibitory to bacterial antibiotic biosynthesis. Phytopathology 87:1250-1257.

Duffy, B. K. and Défago, G. 1999 Environmental factors modulating antibiotic and siderophore biosynthesis by Pseudomonas fluorescens biocontrol strains. Appl. Environ. Microbiol. 65: 2429-2438.

Dwivedi, D. and Johri, B. N. 2003. Antifungals from fluorescent pseudomonads: Biosynthesis and regulation. Curr. Sci. 85: 1693-1703.
Ferreira, A., O’Byrne, C. P. and Boor, K. J. 2001. Role of $\sigma^{\mathrm{B}}$ in heat, ethanol, acid, and oxidative stress resistance and during carbon starvation in Listeria monocytogenes. Appl. Environ. Microbiol. 67:4454-4457.

Ishikawa, R., Shirouzu, K., Nakashita, H., Lee, H. Y., Motoyama, T., Yamaguchi, I., Teraoka, T. and Arie, T. 2005. Foliar spray of validamycin A or validoxylamine A controls tomato Fusarium wilt. Phytopathology 95:1209-1216.

Karus, J. and Loper, J. E. 1995. Characterization of a genomic region required for production of the antibiotic pyoluteorin by the biological control agent Pseudomonas fluorescens Pf-5. Appl. Environ. Microbiol. 61:849-854.

Keel, C., Weller, D. E., Natsch, A., Défago, G., Cook, R. J. and Thomas, L. S. 1996. Conservation of the 2,4-diacetylphloroglucinol biosynthesis locus among fluorescent Pseudomonas strains from diverse geographic locations. Appl. Environ. Microbiol. 62:552-563.

Kets, E. P. W., Galinski, E. A., de Wit, M., de Bont, J. A. M. and Heipieper, H. J. 1996. Mannitol, a Novel bacterial compatible solute in Pseudomonas putida S12. J. Bacteriol. 178:66656670 .

KeU, C., Schneider, U., Maurhofer, M., Voisard, C., Laville, J., Burger, U., Wirthner, P., Haas, D. F. and Défago, G. 1992. Suppression of root diseases by Pseudomonas fluorescens CHAO: Importance of the bacterial secondary metabolite 2,4-diacetylphloro-glucinol. Mol. Plant-Microbe Interact. 5:4-13.

Kim, Y. C., Jung, H. Kim, K. Y. and Park, S. K. 2008. An effective biocontrol bioformulation against Phytophthora blight of pepper using growth mixtures of combined chitinolytic bacteria under different field conditions. Eur J. Plant Pathol. 120:373-382.

Kim, Y. C., Lee, J. H., Bae, Y.-S. Sohn, B.-K. and Park, S. K. 2010. Development of effective environmentally-friendly approaches to control Alternaria blight and anthracnose diseases of Korean ginseng. Eur. J. Plant Pathol. 127:443-450.

Lee, E. H. 2009. Biological control activity of Fusarium wilt in tomato using Pseudomonas sp. NJ134. M.S thesis. Chonnam National University. Korea.

Leeman, M., Den Ouden, F. M., van Pelt, J. A., Cornelissen, C., Matamala-Garros, A., Bakker, P. A. H. M. and Schippers, B. 1996. Suppression of Fusarium wilt of radish by co-inoculation of fluorescent Pseudomonas spp. and root-colonizing fungi. Eur. J. Plant Pathol. 102:21-31.

Marjan, B., Peter, B., Frodo, K., Joost, J. B., Keurentjes, I. S., van Loon, L. C. and Bakker, P. A. H. M. 2003. Control of Fusarium wilt of radish by combining Pseudomonas putida strains that have different disease-suppressive mechanisms. Phytopathology 93:626-632.

Matsufuji, M., Nakata, K. and Yoshimoto, A. 1997. High production of rhamnolipid by Pseudomonas aeruginosa growing on ethanol. Biotechnol. Lett. 19:1213-1215.

Mavrodi, O. V., McSpadden-Gardener, B. B., Mavrodi, D. V., Bonsall, R. F., Weller, D. M. and Thomashow, L. S. 2001. Genetic diversity of phlD from 2,4-diacetylphloroglucinolproducing fluorescent Pseudomonas spp. Phytopathology 91: $35-43$. 
McSpadden-Gardener, B. B., Schroeder, L., Kalloger, S. E., Raaijmakers, J. M., Thomashow, L. S. and Weller, A. D. M. 2000. Genotypic and phenotypic diversity of phlD-containing Pseudomonas strains from the rhizosphere of wheat. Appl. Environ. Microbiol. 66:1939-1946.

Nowak-Thompson, B., Gould, S. J., Kraus, J. and Loper, J. E. 1994. Production of 2,4-diacetylphloroglucinol by the biocontrol agent Pseudomonas fluorescens Pf-5. Can. J. Microhiol. 40:1064-1066.

Nyström, T. 2001. Not quite dead enough: on bacterial life, culturability, senescence, and death. Arch. Microbiol. 176:159-164.

Osman, M., Ishigami, Y., Someya, J. and Jensen, H. B. 1996. The bioconversion of ethanol to biosurfactants and dye by a novel coproduction technique. J. Am. Oil. Chem. Soc. 73:851-856.

Park, J. Y., Oh, S. A., Anderson, A. J., Neiswender, J., Kim, J.-C. and Kim, Y. C. 2011. Production of the antifungal compounds phenazine and pyrrolnitrin from Pseudomonas chlororaphis O6 is differentially regulated by glucose. Lett. Appl. Microbiol. 52:532-537.

Raaijmakers, J. M. Bonsall, R. F. and Weller, D. M. 1999. Effect of population density of Pseudomonas fluorescens on production of 2,4-diacetylphloroglucinol in the rhizosphere of wheat. Phytopathology 89:470-475.

Shanahan, P., O'Sullivan, D. J., Simpson, P., Glennon, J. D. and O'Gara, F. 1992. Isolation of 2,4-diacetylphloroglucinol from a pseudomonad and investigation of physiological parameters influencing its production. Appl. Environ. Microbiol. 58:353358.

Shishido, M., Miwa, C., Usami, T., Amemiya, Y. and Johnson, B. K. 2005. Biological control efficiency of Fusarium wilt of
Tomato by nonpathogenic Fusarium oxysporum Fo-B2 in different environments. Phytopathology 95:1072-1080.

Slininger, P. J. and Jackson, M. A. 1992. Nutritional factors regulating growth and accumulation of phenazine-1-carboxylic acid by Pseudomonas fluorescens 2-79. Appl. Microbiol. Biotechnol. 37:388-392.

Vidhyasekaran, P., Sethuraman, K., Rajappan, K. and Vasumathi, K. 1997. Powder formulations of Pseudomonas fluorescens to control pigeon pea wilt. Biol. Cont. 8:166-171.

Werra, P., Péchy-Tarr, M., Keel, C. and Maurhofer, M. 2009. Role of Gluconic acid production in the regulation of biocontrol traits of Pseudomonas fluorescens CHA0. Appl. Environ. Microbiol. 75:4162-4174.

Whister, C. A., Stockwell, V. O. and Loper, J. E. 2000. Lon protease influences antibiotic production and UV tolerance of Pseudomonas fluorescens Pf-5. Appl. Environ. Microbiol. 66: 2718-2725.

Wood, D. W., Gong, F., Daykin, M. M., Williams, P. and Pierson, L. S. 1997. $N$-acyl-homoserine lactone-mediated regulation of phenazine gene expression by Pseudomonas aureofaciens 3084 in the wheat rhizosphere. J. Bacteriol. 179:7663-7670.

Yigit, F. and Dikilitas, M. 2007. Control of Fusarium wilt of tomato by combination of fluorescent Pseudomonas, nonpathogen Fusarium and Trichoderma harzianum T-22 in greenhouse conditions. Plant Pathol. J. 6:159-163.

Yuan, Z., Cang, S., Matsufuji, M., Nakata, K., Nagamatsu, Y. and Yoshimoto, A. 1998. High production of pyoluteorin and 2,4diacetylphoroglucinol by Pseudomonas fluorescens S272 grown on ethanol as a sole carbon source. J. Ferment. Bioeng. 86:559-563. 